\title{
UNINTENDED EXPOSURE TO HALOTHANE \\ IN SURGICAL PATIENTS: HALOTHANE WASHOUT STUDIES
}

\author{
Hanna M. Samulksa, M.D., \\ Samala Ramatah, M.D., \\ aND WILliam H. Noble, M.D., F.r.G.P.(c) ${ }^{\circ}$
}

GaLLoon, IN 1960, suggested that halothane is absorbed by rubber in the anaesthetic circuit. ${ }^{2}$ Two years later the solubility of halothane in rubber, plastic, and soda lime was confirmed by Eger, Larson, and Severinghaus. ${ }^{1}$ This suggests that small concentrations of halothane may be delivered to the patient from anaesthetic circuits even if the vaporizer is shut off. This small concentration becomes important in the light of the papers by Klatskin ${ }^{3}$ and Sawyer. ${ }^{5}$ Klatskin reported that 0.1 to 0.2 per cent halothane precipitated hepatitis in one anaesthetist. Sawyer pointed out that sub-anaesthetic concentration of halothane may be more dangerous than anaesthetic ones.

The present study was designed to establish washout curves for halothane in various anaesthetic systems used in everyday practice. We also tried to eliminate the source of halothane from the anaesthetic systems by progressively removing the rubber tubing and soda lime.

\section{METHODS}

Gas chromatography was used to determine halothane concentrations. Calibration gas cylinders were prepared by a method described by Sawyer."

Gas samples were taken in new plastic disposable syringes and analyzed within one minute. The choice of plastic syringes was justified by an excellent comparison with results of samples taken in glass syringes and analyzed under the same conditions.

All the systems used were equilibrated with one per cent halothane delivered from a Fluotec Mark iI Vaporizer with a constant flow of six litres per minute of oxygen and with a rebreathing bag replacing the patient. Excess gas was vented through the exhaust valve. After one hour of equilibration a gas sample was taken and checked to insure that it contained one per cent halothane. The vaporizer was then shut off. All samples were taken at the same six litre per minute flow of oxygen and at the same time intervals from the moment of turning off the vaporizer.

The experiment was concluded when either no traces of halothane could be detected, or five hours had been reached. In a few instances in which halothane continued to appear, studies were prolonged to nine hours.

The following systems were analyzed:

(I) an anaesthetic machine without rubber tubing or soda lime container

'From the Dept. of Anaesthesia, University of Toronto and St. Michael's Hospital.

Canad. Anaesth. Soc. J., vol. 19, no. 1, January 1972 


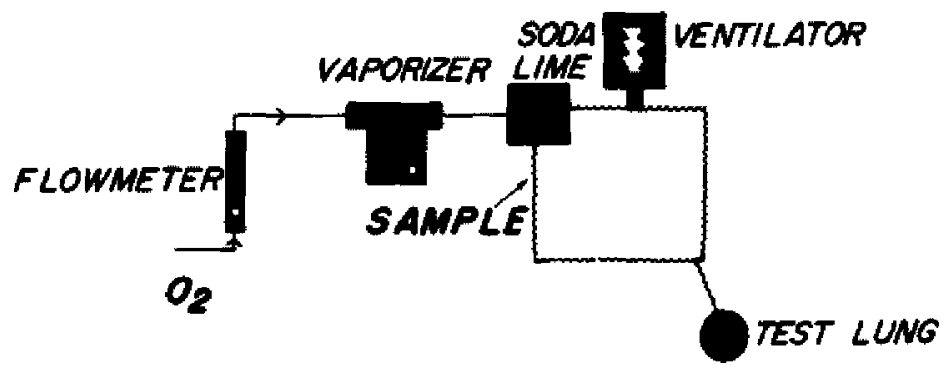

Figune 1. Diagrammatic representation of anaesthetic machine with circle system. Arow indicates sampling point in the system.

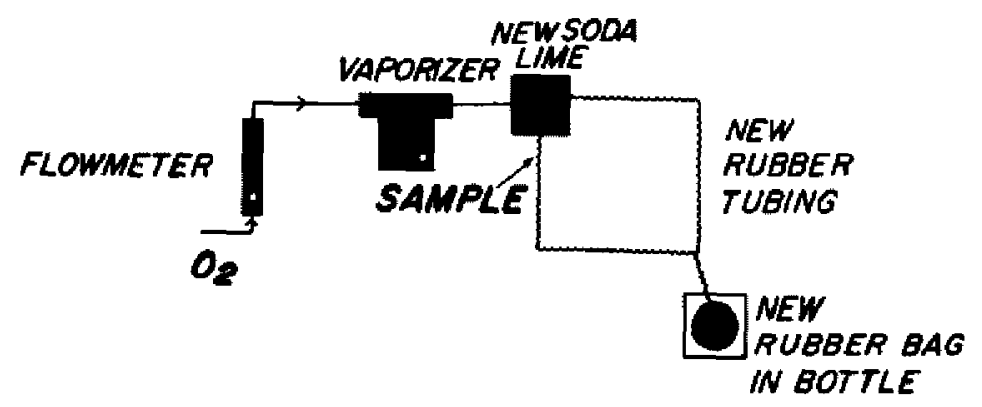

FIGURE 2. Diagrammatic representation of anaesthetic machine with exposed rubber and soda lime replaced by new materials.

(2) an anaesthetic machine with a single rubber tube,

(3) an anaesthetic machine with a circle system, soda lime in a jumbo container, and an Air Shields Ventilator with a test lung (Figure 1).

In an attempt to eliminate the sources of halothane we then investigated:

(4) an anaesthetic machine with a circle system, Air Shields Ventilator and test lung, but an empty soda lime container,

(5) an anaesthetic machine with a circle system, an Air Shields Ventilator, but without the test lung. After equilibration with halothane, new disposable tubing and soda lime replaced materials which had been exposed to halothane.

(6) an anaesthetic machine and circle system without the Air Shields Ventilator. By placing a disposable bag inside a bottle and ventilating the bottle, gases were moved around the circuit. This allowed replacement of all the rubber with a new disposable set. In this system the soda lime was also changed (Figure 2).

In a further attempt to remove halothane from the rubber tubing the exposed rubber was washed with soap used in the operating rooms and the washout curves of halothane were again plotted.

The final step was to analyze gas samples taken from various anaesthetic machines ready for use in the operating rooms after a thirty second flush of a six-litre per minute oxygen flow. 


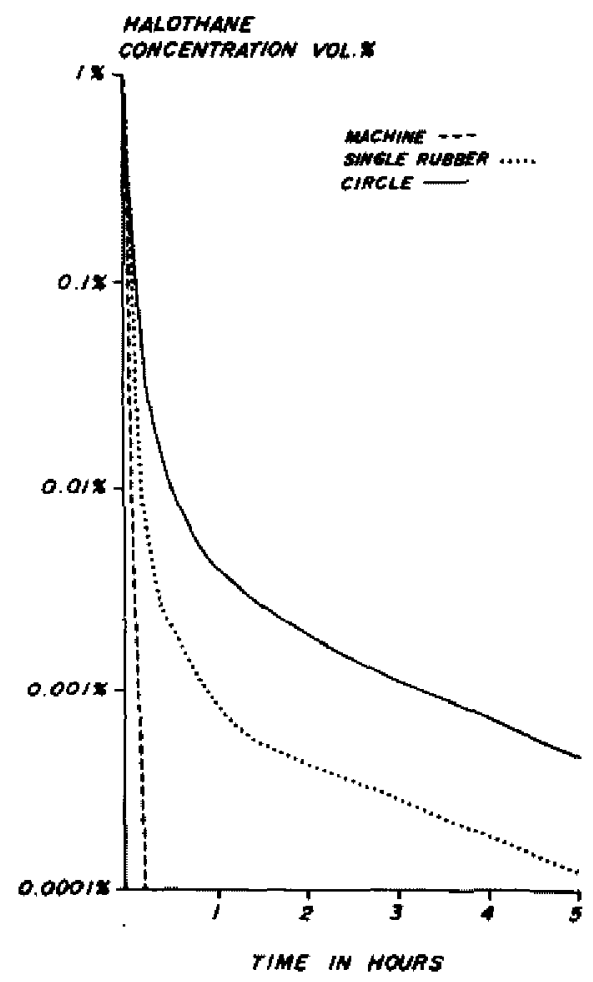

Figure 3. Washout curves for halothane from the first three systems.

\section{RESULTS}

Washout curves for the systems investigated are presented in Figures 3 and 4. Figure 3 indicates that within twelve minutes the anaesthetic machine without rubber tubing or soda lime is washed clear of detectable halothane. As rubber and soda lime are added to the system the washout time of halothane is prolonged. With a single rubber tube five hours of washout time reduced the con centrations to 0.00015 per cent halothane. With a circle system, five hours of washout time reduced halothane concentrations to 0.0007 per cent. In two cases there was still 0.00025 per cent halothane at nine hours with the circle system.

Figure 4 shows washout curves from the last four systems. The circle system is represented by the upper line and is repeated from Figure 3. As exposed rubber and soda lime are replaced with new soda lime and new disposable rubber tubing, the washout time of halothane is shortened. Removing soda lime reduces the five hour concentration to 0.0005 per cent. Replacing soda lime and tubing, but leaving the ventilator in place drops the five hour halothane concentrations to 0.0001 per cent. Full replacement of rubber, soda lime and the ventilator reduces the washout to ninety minutes. 




Ficure 4. Washout curves for halothane as exposed materials are replaced. The upper curve is repeated from Figure 3.

Washing tubes with soap did not change the shape of the curves.

The high, low, and mean halothane concentrations from operating room machines ready for use are presented in Table I. Concentrations of halothane found since December 1970, have generally tended to be lower than those before. This can be explained by the reduced use of halothane in our hospital. During the first six months of 1971 the use of halothane has declined approximately 75 per cent.

On two occasions, during a halothane anaesthetic, a sample of operating room air was taken at the level of the anaesthetist's nose. Halothane concentrations were 0.00036 per cent and 0.00032 per cent.

TABLE I

HaLothane Concentrations

DeEIVERED from Operating RoOM MACHINES READY FOR USE

\begin{tabular}{ll}
\hline Highest conc. & 0.139 per cent \\
Lowest conc. & 0.0003 per cent \\
Mean conc. & 0.0571 per cent \\
\hline
\end{tabular}

Discussion

The washout of halothane from an anaesthetic system is proportional to:

(1) the vapor concentration in rubber - if a near-zero circuit concentration is maintained by a high flushing rate for the system. 
TABLE II

Summary of Halothane Concentrations Delivered from the EXPERIMENTAL Systems at 10 MIN, 1 HOUR, aND 5 HoUts

\begin{tabular}{|c|c|c|c|c|}
\hline SYSTEM & & $10 M I N$. & l HR. & 5 HRS. \\
\hline MACHINE & $=-2-1$ & $.0015 \%$ & & \\
\hline SINGEE RUBBER TUBE & 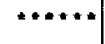 & $.005 \%$ & $.0007 \%$ & $.00015 \%$ \\
\hline CIRCLE + VENTRLATOR & & $+045 \%$ & $.004 \%$ & $.0007 \%$ \\
\hline CIRCLE - NO \$OOA LIME & n......... & $.015 \%$ & $.003 \%$ & $.0005 x$ \\
\hline NEW SODA LIME + TLBING & & $.0045 \%$ & $.0008 \%$ & $.0001 \%$ \\
\hline $\begin{array}{l}\text { NEN SODA LIME + TUEING } \\
\text { + VENTILATOR }\end{array}$ &  & $.0055 \%$ & .00034 & \\
\hline
\end{tabular}

(2) rubber-gas, and soda lime-gas partition coefficients, which for any particular agent are constant.

(3) the surface area of the systems,

(4) the square root of the diffusion coefficient of the agent in rubber, which is also constant for a particular agent, and

(5) the square root of time.

From all of these, only two factors can affect the washout time of halothane from rubber and soda lime:

(a) The vapor concentration. This depends to some extent on the flushing rate (since our rate was never high enough to maintain a near-zero circuit concentration). As we did not vary the flushing rate, this could not affect the halothane washout times. However, machines left idle delivered almost the same Halothane concentrations before and after idleness whether this was one day or one week. (b) Surface area. The surface area did have a marked effect on halothane washout curves. Table II summarizes our data and indicates that the highest concentrations delivered for the longest period came from the circuits with the most surface area exposed to halothane. It is noted that the washout from the anaesthetic machine without rubber tubing or soda lime was twelve minutes. With a calculated metal tubing volume of one hundred cc and a six-litre flow of oxygen per minute, nine time constants - therefore an almost-zero concentration of halothane, should be arrived at in nine seconds. The fact that zero concentration was not anived at for twelve minutes indicates that halothane must be adsorbed to metal or corrosion inside the tubing.

These results indicate that almost every patient in the operating room is exposed to halothane. This implies that the reported incidence of post-halothane hepatitis must be too high, for in none of these studies has any account been taken of halothane delivered when the vaporizer was turned off. Secondly, operating room personnel, and especially anaesthetists, probably should be included in any study of the incidence of halothane exposure. As well, case reports of cross sensitization with other agents, such as methoxyflurane must be viewed with suspicion as these cases may have unknowingly received halothane. 
These are very small concentrations of halothane. The significance of these small concentrations is becoming more important. A recent review article pointed out that subanaesthetic concentrations may do harm. Klatskin ${ }^{3}$ was able to precipitate an acute attack of hepatitis characterized by malaise, fever and scor elevation to 700 units following exposure of a sensitized anaesthetist to only 0.1 to 0.2 per cent halothane. This same anaesthetist suffered recurrent episodes of hepatitis each time he was exposed to subanaesthetic concentrations of halothane present in the air of operating rooms in which the drug was being used. Sawyer noted the concentration dependence of hepatic halothane metabolism. The lower concentrations resulted in more metabolism and removal of halothane by the liver. The higher halothane concentration resulted in less metabolism. If the metabolites of halothane are responsible for liver damage, low concentrations of halothane would be more dangerous than high ones. In the light of these facts and speculations, the low concentrations delivered for hours from anaesthetic machines are significant.

Lowe suggested that exposed rubber tubing and soda lime be replaced, to eliminate the source of halothane in patients not intended to receive the agent. Our experiment showed that this reduced the concentration of halothane but did not eliminate it. In fact, by removing all rubber from the anaesthetic circuit and replacing the soda lime, a washout time of 90 minutes would still be required to arrive at a non-detectable level of halothane.

From a practical point of view, exchanging rubber parts and soda lime and flushing for two hours would be difficult. Possible alternatives would include: disposable anaesthetic machines, one machine per agent, a cut-off between flow meters and halothane vaporizers, or a different machine circuit from each vaporizer to the patient. On existing machines a selector switch could move gas from the flow meters directly to the patient thus excluding the halothane exposed circuit but necessitating two different sets of tubing.

\section{Conctusions}

Whether a different anaesthetic agent is used or an anaesthetic machine is idle for days makes no difference to the fact that halothane is delivered for hours from a previously exposed anaesthetic machine. Most patients in operating rooms must receive halothane. With a circle system and the vaporizer shut off, halothane was delivered for more than nine hours.

Samples taken from operating room anaesthetic machines in ordinary clinical use showed the concentrations varying from a low of 0.0003 per cent to a high of 0.139 per cent. These concentrations, although low, cannot be dismissed.

If halothane hepatitis is a hypersensitivity type of reaction, even small amounts of halothane would be responsible for the disease. Therefore, reports of the incidence of post-halothane hepatitis are probably, in every case, too high, since previous workers do not take these small concentrations into account.

\section{RÉSUMÉ}

Qu'on change d'agent anesthésique ou qu'un appareil à anesthésie soit inutilisé 
durant quelques jours ne change rien au fait que l'halothane continue à être admixistré durant des heures d'un appareil qui a déjà contenu cet anesthésique. La plupart des malades des salles d'opération doivent recevoir de l'halothane. Dans un système à circuit et le vaporisateur fermé, l'halothane a continué à être inhalé durant plus de neuf heures.

Des échantillons prélevés des appareils des salles d'opération en usage clinique ordinaire ont montré que les concentrations allaient de 0.0003 pour cent à 0.139 pour cent. Ces concentrations, bien que basses, ne peuvent être négligées.

Si lhépatite à l'halothane est tn type de téaction d'hypersensibilité, même de faibles quantités d'halothane peuvent être responsables de la maladie. Par conséquent, les rapports sur la fréquence de l'hépatite post halothane sont probablement trop élevés, puisque les auteurs précédents ne tiennent pas compte de ces faibles concentrations.

\section{ACKNOWLEDGEMENTS}

We gratefully acknowledge the expert technical assistance of Mr Brian Dober. This work was supported by Ayerst Laboratories.

\section{REFERENCES}

1. Ecer, E. I., Larson, $P_{.}$\& Severinchaus, I. W. The solubility of Halothane in Rubber, Soda Lime and Various Plastics, Anesthesiology, 29: 356 (1962).

2. Galloon, S. The Concentration of Amaesthetics in Closed Circuits with Special Referentes to Halothane. Brit. J. Anaesth., 32: 310 (1960).

3. Klatskin, G. \& Kimbrac, D. V. Recurrent Hepatitis Attributable to Halothane Sensitization in an Anaesthetist. New England J. M., 280: 515 (1969).

4. Lowe, H. I., Titet, J. H., \& HAcLer, J. J. Absorption of Anaesthetics by Conductive Rubber in Breathing Circuits. Anesthesiology, 34: 283 (1971).

5. Sawyef, D. C., Eger, E. I., Bahlman, S. H., Cillem, B. F., \& Imperman, D. Concentratration Dependence of Hepatic Halothane Metabolism. Anesthesiology, 34: 230 (1971).

6. Bruce, D. L., \& WINGARD, D. W. Anesthesia and the Immune Response. Anesthesiology 34: $271(1971)$. 